\title{
Understanding and actioning BRE environmental assessment method: a socio-technical approach
}

\author{
Martine Spinks* \\ Bartlett School of Planning, University College London, Wates House, 22 Gordon Street, London \\ WCIH OQB, UK
}

(Received 6 February 2013; accepted 2 August 2013)

\begin{abstract}
The following research applies a socio-technical approach to an original study of the role of BRE environmental assessment method (BREEAM) in sustainable building practice. The primary objective is to gain insight into what facilitates and what weakens professional associations to implement a sustainability agenda in a building project. It focuses on understanding different sets of meaning which underlie engagement with BREEAM and how BREEAM is actioned. To do this, the research framework draws on social network analysis. However, this research does not consider that sustainable building is merely an outcome of planned action. Instead, sustainable building is seen to involve processes of engagement amongst different groups, technologies, materials and methods. Therefore, the conceptual framework adopted incorporates consideration of the materiality of sustainable building engagements, highlighting the relations between actors. Interviews with project professionals involved in a case study of a BREEAM Outstanding development provide the empirical basis for this work. This research will be of interest to scholars interested in socio-technical approaches to building development, environmental building assessment methods and sustainable building.
\end{abstract}

Keywords: BREEAM; socio-technical; sustainable property development; meaning making; professional networks; environmental building

\section{Introduction}

There is no agreement as to what sustainability means. In practice it is often seen as an attainable goal: something set by organisations and achieved through institutionalised, routinised practices (Shediac-Rizkallah and Bone 1998). It may be quantified and measured, for instance, as a series of key performance indicators (Rydin 2010). Such conceptions encourage the view that sustainability exists in a relatively steady state - that it can be fixed within a set time and a specific space. This view is arguably at odds with more established understandings of sustainable development as a process: that development should be approached as trans-boundary, participatory action spreading across actors and across generations (WCED 1987, Davidson and Frickel 2004). Implementing a sustainability agenda may be better considered a process of engagement. It involves the coming together of political, social, economic, environmental and technical actors in networks of activity. In the

\footnotetext{
*Email: m.spinks@ucl.ac.uk
} 
urban context, implementing a sustainability agenda focuses on activity within networks of natural, built and social environments (Haughton and Hunter 2003). These networks take form in the development process - processes of building site selection, sale/let, design, planning, construction and operation.

No precise definition of a sustainable building exists either. This is possibly due to conceptualisations of the building process, wherein the building process is often seen as highly divisible. Building practices tend to be segmented according to the division of labour organised amongst professionals associated with a stage of a building project. Building sustainability may therefore be seen as an outcome of such staged activity.

A common example of conceptualising building sustainability as an end-product is the UK BRE environmental assessment method (BREEAM) rating. Similar to its American green building counterpart, leadership in energy and environmental design, this environmental assessment method is a privately accredited standard through which developers and designers meet specific environmental targets in building. Buildings are then awarded an overall score: Pass, Good, Very Good, Excellent and, since 2008, Outstanding (BRE 2008, Lee and Burnett 2008). While at its core BREEAM is an environmental assessment method, in the UK it has become the de facto measure for describing building sustainability. For example, Rydin (2010) declares:

There are a wide variety of schemes now in place to measure the sustainability of new developments and to define in practice what a sustainable building is. In the UK the prime measure used in relation to commercial buildings is BREEAM. (p. 75)

Van der Wetering and Wyatt (2011) echo this: "The most commonly used tool for assessing the wider sustainability performance of new buildings in the UK is the BREEAM" (p. 31). Van der Wetering and Wyatt (2011) go on to state that BREEAM assesses a broad spectrum of environmental areas in building, and in doing so, "the instrument is used to obtain a sustainability rating for the building" (p. 31). BREEAM is not just an environmental assessment method. It is seen more broadly as a generally accepted measure of sustainable building. It is against this which the effects of BREEAM may be evaluated.

This work adopts a socio-technical network approach to analyse actor engagements within a BREEAM-certified building project. The primary research aim is to gain an understanding of what facilitates and what weakens associations within a sustainable building project. This includes exploration of the meanings that project actors attach to BREEAM and how project professionals action BREEAM objectives. This is important to study for, in the words of Rydin (2010), "the details of the operation of a tool such as BREEAM are significant since they shape what it means to build more sustainably and they can shape practices of development themselves" (p. 76). The next section explores the socio-technical framework applied to this research. This includes discussion of the main theoretical concepts adopted. Thereafter the case study is introduced: 7 More London, England's first BREEAM Outstanding-rated office building. A discussion of BREEAM is followed by an explanation of methods for empirical research, including semi-structured interviews with professionals involved in the case study project. Finally, the case study findings are discussed.

\section{Socio-technical approach to networks}

This research adopts a socio-technical framework for the exploration of action. This framework borrows from social network analysis (SNA) whilst also incorporating elements of 
materiality to highlight relations between actors. This section begins with a brief introduction of some key features of SNA before introducing the framework developed for this study. This includes discussion of norms, power and networks.

While often the technological side of building is cited in the literature on sustainable building, sustainability is also a social issue (Haughton and Hunter 2003, Rydin 2010)). It is both a concept and a practice constructed by related groups. SNA is useful to study the points of commonality and difference between such collectives - social groups of individuals with common interests and objectives (Sandhu and Helo 2006). A defining feature of SNA is that it explains action through the institutional or organisational values to which actors are socialised. These values, in turn, drive the pursuit of objectives. Put another way, SNA considers that actors are socialised to discrete sets of norms and rules of the respective organisations and institutions to which they belong. This is seen to affect actor behaviour vis-à-vis others within their associated networks (Tindall and Wellman 2001, Holman 2008).

SNA is useful to identify weaknesses in organisational and institutional dynamics. This enables proactive measures to be taken to strengthen some network ties over others and enable the strategic positioning of some actors within power structures. Actors can then exert strategic influence over others and assert their norms, values and opinions within the network (Holman 2008). Yet, critics, including some Actor-network Theorists, contend that implicit to this is an analytical bias favouring the positioning of one group of actors over another; that it offers no breathing space from conflicts of power (Latour 1987, Elam 1999).

Other critics of SNA point out that the theory is overly focused on the social realm; that it does not account for the effects that material elements can have on the relations between actors (Latour 1999, Tindall and Wellman 2001). The argument is that a theory so closely tied to social interests, values and norms separates social action from objects. Put another way, materials are treated as either a reflection of or a resource for the contexts that shape social action (Latour 1993). Yet, material elements can have agency themselves (Johnson 1988); they can effect relations between actors. To paraphrase Latour (1999), if social actor identity is at all defined by the resources (in this context meaning the non-social actors) they have access to, as well as by the series of associations in which they are involved, then social actors are at minimum influenced by non-social actors. Non-human agency may be an effect of previous relations - a relay of relations in its network. It is also possible for non-social elements to actively intervene in the course of relations and direct action. In other words, action may be explicitly hybrid - both an outcome of and an influence on multi-variant actor-network associations (Callon and Law 1997). Thus, Latour (1999) implores, "[w]e must learn to attribute - redistribute - action to more agents than are acceptable in either the materialist or the sociological account" (p. 180). To this end material entities should not be treated as separate from either social actors or their socially mediated contexts. Instead, materiality should be approached relationally with the social; "as the formed pattern in which a particular entity takes part and which allows it to relate in particular ways to (an)other particular entity(ies) (Sørensen 2007). In this way, materiality may be seen as a distributed effect of actor association.

Building upon this, the socio-technical approach developed here is largely based on SNA; however, it broadens the theory to include materiality elements to highlight relations between actors. In doing so it allows for the exploration of patterns of association across socio-material networks.

The concept of the network is useful to capture and explain the connections amongst agents that enable action or, conversely, disallow action. Networks constitute an 
opportunity for agents to initiate effects in their environment: they embody the capacity to act, the potential for interaction and the effects of agency. Law (1999) states that, "in a network, elements retain their spatial integrity by virtue of their position in a set of links or relations" (p. 6). The definition of an agent is associated with its position within the network. Therefore defining an agent necessitates defining the point of commonality that binds the agent and a network together.

Metaphorically, a network is less a trajectory and more a repository for the connections between actors. Within these repositories, there is a degree of density or cohesion amongst some elements of the network. Degrees of density can strengthen network connections and, effectively, the assertion of power. Put another way, the stronger the ties between agents in a network the greater the capacity of powerful actors to affect some control (Latour 1999, Doak and Karadimitriou 2007). The approach adopted here marries the SNA contention that power involves the assertion of norms, values and opinions within a network whilst also taking into account the processes of network formation, the strength of ties and the effects of materiality generated through patterns of socio-technical relations. This sociotechnical framework will be used to question both what and how meaning is understood and actioned. This is explored in detail in Section 5. However, first the case study used for such an analysis requires introduction. The next section presents 7 More London, a BREEAM Outstanding-rated building, which is used as the empirical basis for this work. The socio-technical approach presented above will be applied to an analysis of this building's sustainable development processes.

\section{The sustainable building process: introducing a case study development}

Sustainable building is both a social and a physical construct. As a social construction, it involves a process of interaction amongst different groups with the shared goal of addressing and producing action that will progress a sustainability agenda. As a physical construction, a sustainable building is a process of technical engagement of materials and system flows which collectively contribute to the production of a structure that fulfils the principles of a sustainability agenda. Sitting behind both these processes are socio-technical networks. Within these networks individuals, groups, technologies, materials and methods interact. What is more, socio-technical associations take on new forms, meaning and identity dependent upon the ways in which socio-technical relations are organised. However, it is one thing to speculate, theoretically, on the existence of socio-technical networks. It is quite another to capture processes of relation across entities involved in a sustainable building. This paper attempts to do just that though. The case study building used for this research is 7 More London, a large-scale, single-use, sole tenanted building and the first BREEAM Outstanding-rated office in England. Interviews with professionals engaged in 7 More London's development process identify and isolate socio-technical associations across networks involved in activity meant to progress a sustainability agenda. The following two sections introduce the case study BREEAM Outstanding building and present methods for both data collection and analysis. Findings stemming from this empirical research are then discussed.

\subsection{Case study building: 7 More London}

Nestled between Tower Bridge and London Bridge on London's Southbank is Number 7 More London Riverside (7 More London). This new, purpose-built office space is tenanted by PricewaterhouseCoopers Limited Liability Partnership (PwC) and owned by More 
London Development Limited (MLD). MLD was responsible for developing the design of the building shell and core and taking it to an agreed level of tenant specification. In contrast, $\mathrm{PwC}$, a global professional-services firm, was responsible for the fit-out (FO) design and contracting construction of the building's interior before engaging facilities managers. From the outset of negotiations between the developer and occupier, achievement of a high BREEAM rating was central to the design and development of the new building. As previously mentioned, BREEAM is a building environmental assessment method which scores primarily new developments against pre-determined environmental building credit categories. Some of the criteria are mandatory, meaning that all projects must attain a minimum score in certain credits to be eligible for complete assessment. Subsequently a quality floor is set (Hamedani and Huber 2012). BREEAM pre-requisites depend on the level of certification the building is targeting. For example, what is required of a "Good" building may not be necessary for a "Pass" building. The outcomes of building design and performance are totalled into an overall credit score: Pass $\geq 30 \%$, Good $\geq 45 \%$, Very Good $\geq 55 \%$, Excellent $\geq 70 \%$ and Outstanding $\geq 85 \%$. This tiered system is set with the intention of ensuring that the higher quality "Excellent" and "Outstanding" buildings are designed with key sustainability targets in mind (Reed et al. 2010).

In 2008, during a period of intense activity on 7 More London's base-build (BB) enclosure, the organisation responsible for BREEAM (the BRE) launched the "Outstanding" BREEAM rating as part of their biennial update to the building assessment scheme. A rigorous programme of design revision led by $\mathrm{PwC}$ concluded with the building being accredited as the first BREEAM Outstanding office building in England (BDP 2009a, 2009b). Whereas the highest overall score was previously $70 \%$ and above for Excellent, Outstanding is awarded based on scores of $85 \%$ and higher. To be awarded such credit, aspects of a development must be proven to meet or exceed pre-defined BREEAM Outstanding requirements in almost every credit category, including: management, health and well-being, energy, transport, water, materials, waste, pollution, and land use and ecology. They might also be considered pioneering to the sustainable building process and awarded Innovation credits. To gain credit in the Innovation category, a representative from the project team must apply to the BRE for it to determine whether a building feature or part of a sustainable building process should be awarded innovation points (BRE 2008). For example, 7 More London was awarded an innovation credit for its role as an exemplary learning resource. Video technologies on each floor of the headquarters are dedicated to educating building users about sustainability aspects of the development. It was proposed to the BRE that through this medium occupiers will learn about the sustainable features of the building and their behaviours will change accordingly, for instance, by recycling more. Table 1 summarises 7 More London's performance against the BREEAM 2008 credit categories and maximum achievable scores. It shows that 7 More London would not have achieved a BREEAM Outstanding score if it were not for the award of credits in the Innovation category.

That boundaries of building standard analysis are overly rigid has long been a critique of building assessment. Critics contend a challenge is that they are too focused on individual building performance and not engaged enough with local contexts (Cole 1998). Other critics, including Lowton (1997) and Ding (2005), have found that high environment building assessment scores equate to project overruns, particularly where such considerations are not fully understood early in the development process. Van der Wetering and Wyatt (2011) note BREEAM appraises the potential performance of primarily new buildings, "and therefore misses the substantial challenge of improving the environmental performance of existing buildings" (p. 31). They average that $1-2 \%$ of office stock additions in any given year 
Table 1. BREEAM score sheet for 7 More London (BDP 2009b, BRE 2008).

\begin{tabular}{|c|c|c|c|}
\hline \multicolumn{2}{|l|}{ Credit category } & $\begin{array}{c}7 \text { More London } \\
\text { weighted score (\%) }\end{array}$ & $\begin{array}{l}\text { Maximum score } \\
\text { achievable (\%) }\end{array}$ \\
\hline \multicolumn{2}{|l|}{ Management } & 12.00 & 12.00 \\
\hline \multicolumn{2}{|l|}{$\begin{array}{l}\text { Health and well- } \\
\text { being }\end{array}$} & 10.38 & 15.00 \\
\hline \multicolumn{2}{|l|}{ Energy } & 16.63 & 19.00 \\
\hline \multicolumn{2}{|l|}{ Transport } & 8.00 & 8.00 \\
\hline \multicolumn{2}{|l|}{ Water } & 5.00 & 6.00 \\
\hline \multicolumn{2}{|l|}{ Materials } & 5.77 & 12.50 \\
\hline \multicolumn{2}{|l|}{ Waste } & 6.43 & 7.50 \\
\hline \multicolumn{2}{|l|}{ Land use and ecology } & 8.00 & 10.00 \\
\hline \multirow[t]{4}{*}{ Pollution } & & 5.83 & 10.00 \\
\hline & Total & 78.04 & \\
\hline & $\begin{array}{l}\text { Additional innovation } \\
\text { credits awarded }\end{array}$ & 8.00 & (Not set) \\
\hline & Total BREEAM score & 86.04 & 100 \\
\hline
\end{tabular}

are newly constructed. The remaining building works fall largely to renovation programmes. Moreover, while there is no central data bank holding information related to the location, age, number and type of BREEAM-rated commercial buildings in England (largely owing to data protection laws), survey evidence indicates that BREEAM may be used more for "flagship" developments, such as 7 More London. Such buildings tend to involve higher-cost designs and are developed, in part, to communicate a sense of prestige related to corporate identity (Miller and Buys 2008, Fuerst et al. 2011, Van der Wetering and Wyatt 2011).

BREEAM is not a black and white scorecard system. Contention envelops its methods, its meaning and the subsequent sustainable development processes undertaken in its name. Therefore, this research does not only review the BREEAM credits that 7 More London attained. It also explores the qualitative side of the sustainable building process. The research methods are outlined below.

\section{Research methods}

Semi-structured interviews were undertaken with a sample of 34 BB and FO professionals directly engaged in 7 More London's development lifecycle. This type of interview is based upon a proforma of subject areas that shape the direction of discussion. Prior to arranging interviews the researcher developed an interview guide for the sessions, including the following three thematic areas which were explored: (1) how different professionals interpret BREEAM and how meaning is constructed, (2) how professionals action BREEAM objectives and (3) what type of approach to building practice BREEAM supports. Questions were not provided ahead of time to participants. Instead, they acted as a guide to the research to help stimulate the flow of conversation. All interviews were recorded by the researcher and transcribed by a professional.

Each participant signed an interview consent form, permanently transferring the recorded and transcribed data to the researcher. Participants also consented to the researcher's use of the resultant information for publication. They were given the option to access their recording and/or transcript at any time throughout the study period, to be given a copy of the research results and to withdraw from the research process should they feel the need 
to do so. Finally, all participants were granted anonymity to the extent their names were not to be disclosed. However, it was explained that their roles and respective organisations would be named as the research sought to understand relations, meaning and the role of power amongst the building's socio-technical networks.

After four pilot interviews were conducted, participants were recruited through convenience and snowball sampling. The researcher secured senior-level staff endorsements for this study from both BB and FO sides of the development. Such individuals were instrumental in recommending and facilitating subsequent interviews. Thereafter a process of snowball sampling took place. Snowball sampling is an efficient method to use in focused network studies: eventually participant suggestions will be exhausted and the network of relations will close on itself (Schutt 2008). In the instance of this field work, the network closed on itself after 34 one-hour-long interviews were completed over a period of two months. Network closure was indicated by increasing repetition of suggested contacts (i.e. those who were already interviewed) or continued lack of response by individuals whom the researcher attempted to contact. A list of organisations that participated in the study is shown in the appendix.

A list summarising the 34 professionals interviewed and the level of their involvement in the BREEAM process is shown in Table 2. A ranking of high, medium and low was used to categorise their level of involvement with BREEAM. "High" was defined as having 12 or more interviewees refer to a professional as being directly involved in building sustainability through engagement with BREEAM. "Medium" is assigned to those individuals who were referred to as being directly involved in building sustainability through engagement with BREEAM by 6-11 interviewees and "low" refers to those mentioned by 5 or fewer study participants. Results of interest include a Landscape Architect, who was ranked by interviewees as being involved at a high level. However, this Landscape Architect declared neither he nor his colleagues had any involvement in the BREEAM process. The BREEAM Assessment Manager working on behalf of the BB team also declared his involvement in the BREEAM process as minimal, partly due to the fact that he only interacts with the BRE and that other project team members do not understand what he does. A BB Cost Consultant declared his role as integral to the BREEAM process because of his organisation's control over costs and, effectively, what is "in" versus "out" of the building. Yet, no other interviewees supported this perception that the BB Cost Consultants were highly involved in the BREEAM process. While it is not necessary that all professionals involved in a building development have the same understanding of what BREEAM is, it is fair to assume that otherwise key players in a project team share a similar meaning of who and what the method should involve. A BB Construction Engineer thought that core project team members should have a general understanding of what BREEAM is whereas, "a buyer, a tenant, or someone ... they just want to know where it hits for the final score".

Data were analysed with the aid of ATLAS.ti, a qualitative analysis software. ATLAS.ti is a knowledge management and analysis tool; it allows users to code and build theories based on relational analysis of information. The researcher is able to upload transcripts of interviews and save them in a megafile on the software itself. This then acts as a platform for the codification of data and grouping of codes into families of similar information sets. ATLAS.ti is also a graphical tool that allows users to visually and systematically relate data sets to one another through representations on network maps (Barry 1998, ATLAS.ti 2009). Coviello (2005) argues network maps are useful representations of such associations. They facilitate understanding of how and why ties amongst network agents are developed. Drawing on codified data sets created through ATLAS.ti, network maps were created for 
Table 2. Summary of interviewed professionals' roles and the level of their perceived involvement in the BREEAM process.

\begin{tabular}{|c|c|c|}
\hline Professional & $\begin{array}{l}\mathrm{BB} / \mathrm{FO} / \\
\mathrm{GB}\end{array}$ & $\begin{array}{c}\text { Perceived level of engagement with BREEAM? } \\
\text { (high/medium/low) }\end{array}$ \\
\hline Real Estate Director & FO & High \\
\hline Project Manager & FO & Low \\
\hline Environmental Engineer & FO & High \\
\hline Main Contractor & FO & Medium \\
\hline Lead Developer & $\mathrm{BB}$ & High \\
\hline Development Project Manager & BB & High \\
\hline Main Contractor & $\mathrm{BB}$ & High \\
\hline Cost Consultant & FO & Low \\
\hline Services Contractor & BB & Medium \\
\hline Architect & BB & High \\
\hline Structural Engineer & FO & Medium \\
\hline Mechanical Contractor & BB & Low \\
\hline Electrical Contractor & BB & Low \\
\hline BMS Contractor & $\begin{array}{l}\text { BB and } \\
\text { FO }\end{array}$ & Low \\
\hline Sprinkler Contractor & BB & Low \\
\hline M\&E Cost Consultant & $\mathrm{BB}$ & Low \\
\hline Head of Data Centre & BB & Low \\
\hline $\begin{array}{l}\text { UK Operations and Global Facilities } \\
\text { Functions }\end{array}$ & $\mathrm{FO}$ & High \\
\hline Lighting Specialist & FO & Low \\
\hline Landscape Architect & FO & High \\
\hline Specialist Ecologist & FO & High \\
\hline Development Control Team & GB & Low \\
\hline BREEAM Assessor & BB & High \\
\hline Services contractor & BB & Low \\
\hline Case Officer & GB & Medium \\
\hline Public Health Engineer & $\mathrm{BB}$ & Medium \\
\hline Interior Designer: Materials & $\mathrm{FO}$ & Low \\
\hline $\begin{array}{l}\text { Head of Building and Facility } \\
\text { Services }\end{array}$ & $\mathrm{FO}$ & Low \\
\hline IT Manager & FO & Low \\
\hline Maintenance & FO & Low \\
\hline Head of Catering & FO & Low \\
\hline Construction Engineer & BB & Medium \\
\hline Site Commissioning Manager & $\mathrm{BB}$ & Low \\
\hline Site Supervisor & BB & Low \\
\hline
\end{tabular}

Note: GB, government body.

professionals involved in the 7 More London building project. However, a shortcoming is that ATLAS.ti network maps present all relational ties simultaneously. Subsequently network maps for some key actors involved, for instance, BB Developer, were too dense to be of use. This is a limitation of the software: that too much information is presented graphically to be reproduced with any meaning. Therefore, using ATLAS.ti this study created network maps for those actors cited by interviewees as (1) having close association with achieving BREEAM certification for the building and (2) having clear boundaries of involvement, usually defined according to the stage of building development in which they are primarily engaged (i.e. the construction stage) or having small relational networks. These ATLAS.ti maps are used for illustrative purposes in the following discussion. 


\section{Results and discussion}

\subsection{Understanding BREEAM}

Core project team members on both BB and FO sides of the development, including the lead architects, engineers, project managers and cost consultants, tended to share a common understanding that a level of prestige was attached to BREEAM-rated buildings. BREEAM was seen to bring with it publicity, impacting the perceptions of both the building itself and those who are associated with it. For example, one FO Main Contractor interviewed thought that:

PwC do it for the kudos of saying they've got an Outstanding building and they're the first ones to get that Outstanding building and they balance that against, 'are we actually doing something good for the environment and are we actually getting a lot of press coverage out of getting an Outstanding BREEAM rating?'

Similarly an FO Project Manager perceived that 7 More London's upgrade from BREEAM Excellent to BREEAM Outstanding will ensure, "some reflected glory for the developer, the local authority and the GLA [who are also located on the More London estate] about having a big corporate building that delivers a good sustainability message". Indeed, a BB Developer nicknamed 7 More London the "Jewel in the Crown", reflecting the new build's prominence compared to neighbouring plots. An FO Environmental Engineer also was not shy to proclaim that his firm was "looking to go for all the awards we can on this job", and that the BB Architects are "badge collectors", becoming involved in sustainable building projects for the accolades. These perceptions indicate that a high level of prestige is associated with a highly rated BREEAM building. What is more, this meaning is seen as shared amongst a variety of professionals, for example, from the BB Architects to the local authority.

Meaning travels quickly across networks where actors commonly associate with, and accept, shared objectives. In building networks individual interpretations of objects and objectives are created locally. Seemingly everyday issues and experiences frame people's understandings and subsequent actions. What is more, the stronger and more immediate the links amongst relations within a network, the more likely powerful actors are able to disseminate their views over others (Banerjee and Solomon 2003). This may be seen as a characteristic of network power. As Schweber and Harty (2010) put it, "power resides not in [socio-technical actor] intrinsic characteristics but in the strength of the network in which they are embedded" (p. 672). Strong networks are those in which connections amongst actors are well defined and relatively robust. Within these more stable entities, powerful actors can have significant reach and influence, which can shape the actions of others to correspond with their own sets of meanings (Latour 1999, Schweber and Harty 2010).

PwC were frequently cited as being a powerful actor, sharing and asserting their corporate values and norms across the development lifecycle. One BB Project Manager considered PwC were able to do this because, "they keep their fingers in all the pies... they've had a representative involved at every step of the way", for instance, having FO Facilities Managers involved in design briefings with the BB design team. PwC effectively shortened the distance between themselves and other project team members by inserting themselves into networks across the letting negotiation, briefing, design, construction and, of course, operation stages of the development process. Along a similar vein, a BB Construction Manager speculates that based on the extent of project knowledge held by $\mathrm{PwC}$ representatives who have visited the $\mathrm{BB}$ site, $\mathrm{PwC}$ have effectively communicated 
what they consider to be important to others within the organisation. He explained that the sustainability aspect of the new headquarters figures prominently in the conceptions of the building held by the majority of $\mathrm{PwC}$ representatives whom he met. It is not only that they were aware of key technical features of the physical construction of the building, such as the Combined Cooling and Heating Power kit, but they also expressed a keen understanding that plot 7 is "good for the environment so it's a good building". He added, "I don't think too many people know how [BREEAM] actually works. But as a measure - as an active measure - that the client has taken to try and make the building greener, then a lot of people understand that [a] step has been taken". The inference is that the tenant has disseminated a common understanding that this building, to be rated England's first BREEAM Outstanding office building, is associated with goodness. Simply put, because PwC are "green" they are therefore also "good".

Images held about a corporation effects its reputation and subsequently the attraction of clients and the recruitment and retention of staff. In the corporate world, this can translate into either profit or loss (Riordan et al. 1997, Balmer and Greyser 2003). Larson et al. (1998) list costs, including high administrative costs for selection of replacement workers, training and development costs, and costs of disruption of work in the workplace. They also explain that staff turnover has additional, sometimes hidden, costs such as the negative effects of remaining staff members who re-evaluate their commitment to the corporation. An FO Corporate Real Estate interviewee cited the recruitment and retention of PwC staff as a key driver in producing the best possible building. In his words: "the important thing was recruitment and retention, best place to work, attracting people to the building". Along the same vein a BB Construction Manager and FO Environmental Engineer shared a common understanding that the occupier sought to evoke the image that they are leaders in the marketplace. This was done for the sake of attracting clients to the firm and enhancing their competitiveness: "its [7 More London is] being occupied by a potential tenant who is seriously interested in sustainability because its competitors are - because it has an image to, you know, portray in the market”. A BB BREEAM Assessment Manager also explained:

it's because they've got an image. They're one of the best in the world, best in their class. PwC have a reputation and Ernst and Young [a direct competitor] is just around the corner. So you

know they would like to be responsible, be responsive to the environmental needs.

Taking what an FO facilities management interviewee coined "the sustainability angle" to distinguish themselves from their competitors is a conscious decision. The occupier intentionally sought to influence the perceptions and behaviours of professionals not only active within the project lifecycle, but also of clients and staff who sit beyond the building's design and construction networks.

\subsection{Acting on BREEAM}

As previously mentioned the BREEAM scorecard system acts as a roadmap to achieving environmental standards for a new building. Project teams analyse credit values assigned to BREEAM categories and target actions accordingly. The results are then weighted on a sustainability scorecard. However, not all actors will agree on which credit categories to go for, or the means by which to achieve weighted scores. Different actors will propose achieving different BREEAM credits depending on their areas of expertise. As one BB Cost Consultant put it: 
if you said BREEAM Excellent as an objective, well there's maybe an infinite [number of] different ways of trying to get there. But what you do as a team is you work through [it] and you go for the ones that make [the] most sense and assign [those to team members].

In other words, functional specialists will tend to focus on their areas of expertise. These areas of expertise tend to be ordered and siloed according to the epistemic communities to which their skills belong. For example, the BB Specialist Ecologist was brought in as a consultant to exclusively help the building achieve BREEAM Excellent. For the most part this work was independent of others, depicted in the network map shown in Figure 1. The Ecologist engaged with the BB Design Team (including the BB Developer) only when these actors' technical expertise was seen to affect the Ecologist's specialist role, such as needing to understand the design of the building's roof for the purposes of creating living roofs (both brown and green roofs) onto it.

The living roofs provide ecological benefits by creating new habitats for flora and fauna. For example, integrated into their designs are bird boxes to attract local species, including the protected Black Redstart. Living roofs were central to binding together the BB Specialist Ecologist and materials and suppliers associated with biodiversity and building design. Yet, concentration on the material elements of building ecology also isolated the Ecologist; this work was seen as highly specialist and focused on its own end-product: the achievement of BREEAM credits. The living roofs were erected for ecological purposes stemming from a need to maximise BREEAM credits in the Land Use and Ecology category. They were not tied to any other category and possible sustainable synergies were lost, for example, their contribution to energy management through thermal and cooling

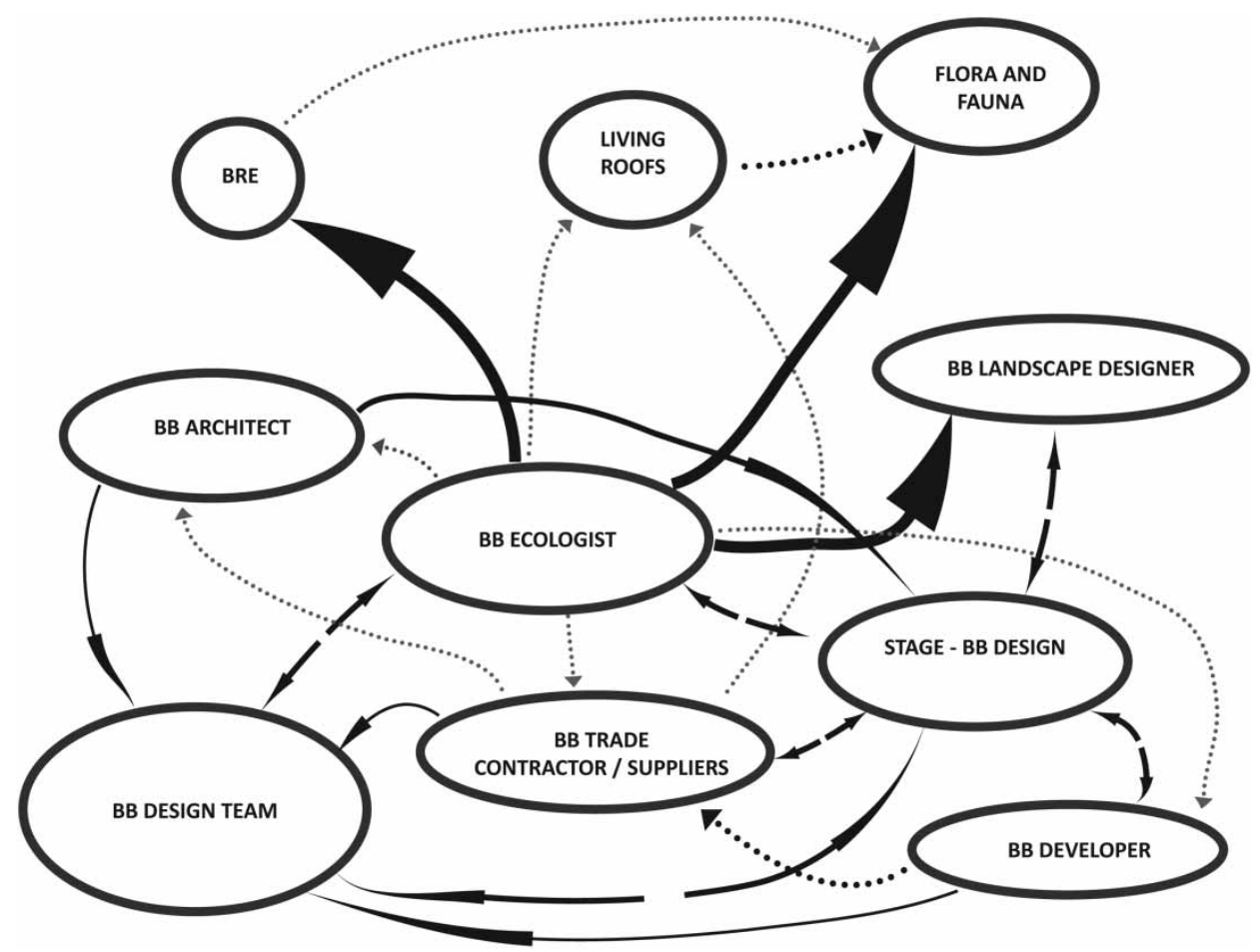

Figure 1. Network map created for the BB specialist ecologist. 
effects. Credit category prescription is something a BB Developer took issue with. In his words:

They're [the BRE] trying to come up with a template that fits all circumstances and it's very difficult for them. I'm not trying to criticize from that point of view. But from the other end it's [i.e. BREEAM] a very rigid, brittle tool and is managed and regulated by a set of people which have limited amount of time and a whole range of different circumstances they're trying to contend with at once. So therefore I can understand why it appears very bureaucratic, inflexible and unintelligent but never the less it doesn't give us the opportunity to deploy flexibility, intelligence.

Both this interviewee and the Specialist Ecologist saw BREEAM categories as prescriptive and limiting ways of doing things.

While BREEAM may be seen as prescriptive, it does not necessarily micro-manage specifications. That is, BREEAM may delimit the ways in which sustainability is engaged with at a building level, but it does not necessarily prescribe requirements at a material level. Project professionals might be bounded by credit categories, but not necessarily by actual supplies. For example, as one lighting manufacturer wrote in relation to the BREEAM offices scheme, "the more efficient the lighting under BREEAM the more points are awarded, but only as an aggregate overall efficiency" (Clearvision 2012). Project professionals have some leeway in how they might go about attaining credits. Yet, where there is leeway in design (such as designing to an aggregate overall efficiency), there is also scope for other social interests to take over. This is what the FO Lighting Consultant thought the FO Main Contractor was doing. In fact, the FO Lighting Consultant thought the FO Main Contractor had the potential to ruin what the FO Lighting Consultant saw as "real" sustainable features of the buiding's design. What happened was that light-emitting diodes (LEDs) were specified in the client brief as an efficient source of lighting. However, the FO Lighting Consultant advocated multi-faceted reflector 16 (MR16) light bulbs, a material often used in desk lighting. In the FO Lighting Consultant's professional opinion LED lights were not yet of a grade that makes them a sustainable option; more than double the number of LED bulbs were needed to achieve the quality of light PwC sought in comparison to the use of MR16s. However, resolution of this debate did not come down to sustainability and material usage for luminaires. Instead it boiled down to an issue of cost. The FO Lighting Consultant explained:

what tends to happen and what's happened on this job is the contractor comes on board and the contractor thinks they can see savings and also thinks they can make more money basically ... So what we do now [is] go back through and review everything and look at all the reasons why we chose that fitting in the first place and if the contractor is offering something that we feel is equal but is cheaper, then that gets signed off. The idea is if it's not equal to the original specified fitting then it won't get signed off. That's not always the case because that is where you start to get the client and the cost consultants getting very involved, again particularly on this project. The client obviously being fairly money wise and they may start to say, "well no we'll just go with that" against our advice.

A result was that the building sought credit in the lighting category; however, it does not do so in what the FO Lighting Consultant considered to be the most sustainable way. Instead, economic considerations outweighed optimal sustainable material selection. However, this is not merely the result of the FO Main Contractor asserting network power. This is also a function of the contracting method employed. 
The FO Main Contractor became active in the project towards the end of the shell and core works, at which time they were appointed by $\mathrm{PwC}$ on a design-bid-build contract. Design-bid-build is a traditional procurement method where the client appoints the main contractor on a fixed-price contract and presents them with a final building design. The main contractor then challenges the specification, for instance, how a specified insulation material compares to alternatives in terms of installation programme, costs and operational efficiency. They then finalise direct agreements with suppliers and sub-contractors in the market, which tend to be at a price that is a percentage of the main contractor's fixed fee (Oyegoke 2001). Thus, there is scope for profit-making through rigorous value engineering. Pryke $(2004,2005)$ criticises what may be described as overly analytical approaches to construction project engagements. He identifies task dependency and hierarchical relations as approaches which disable actors from engaging in adequate levels of detail. Such levels, he contends, are those which reflect complexities, provide clarity and allow for comparison of identified roles and relations amongst project actors within building networks - those which are arguably necessary for the implementation of a sustainability agenda in a building project.

Another critique is that design-bid-build encourages challenges in pursuit of lowest cost and not necessarily sustainability. In this instance the FO Main Contractor found that additional material elements were added into the building design over the year and a half period since the budget was set. This was done to meet BREEAM Outstanding criteria. The FO Main Contractor engaged in a rigorous programme of cost control over the supply chain to bring the associated costs down. As they directly manage the supply chain, the distance between these network connections was short. In an FO Main Contractor's words, "once we get involved in the project we are probably the central person. So as an organisation I think our actions are central because what happens is once the main contractor becomes involved, all the elements tend to feed into us". The FO Main Contractor's network map is shown in Figure 2 to illustrate these more immediate network connections. The effects of network relations are also noted. Connections are labelled as: weakening ties, strengthening ties, affecting the actions of others or of the FO Main Contractor having direct, indirect, limited or significant engagement with others.

Overall, BREEAM was largely found to lead more to a concentration on results instead of a focus on cause - fixation on achievement of a target rather than engagement in process. As a BB Structural Engineer put it, "sometimes people might just be focused on the rating as opposed to understanding what it means". A BB Public Health Engineer supports this conception, he states, "I don't even know if they'd [other 7 More London actors] know how integral it is. I honestly don't know what they've done. I've never talked to anybody about it". In connection, an FO Environmental Engineer considers:

most people don't really know what BREEAM is ... They will create their own feeling for it. They just know it's something that rates the sustainability of the building ... I think there's a lot of people in the industry that just use it like: "we need a BREEAM rating. Which credits do we get for design? Which ones are cheap"? Okay we got our Excellent [rating], done.

A senior BB Architect supports this view: "there're sort of easy points which can be sort of ticked off [for example] because you put cycle spaces in, whereas really it's about the amount of energy a building uses. That's what it should be about". A BB Developer criticises BREEAM for bureaucratising sustainability and for creating a focus on ratings which may not result in optimal building sustainability. This may also be seen as an example of the incorporation of materiality into network constructions: BREEAM as a sustainable building 


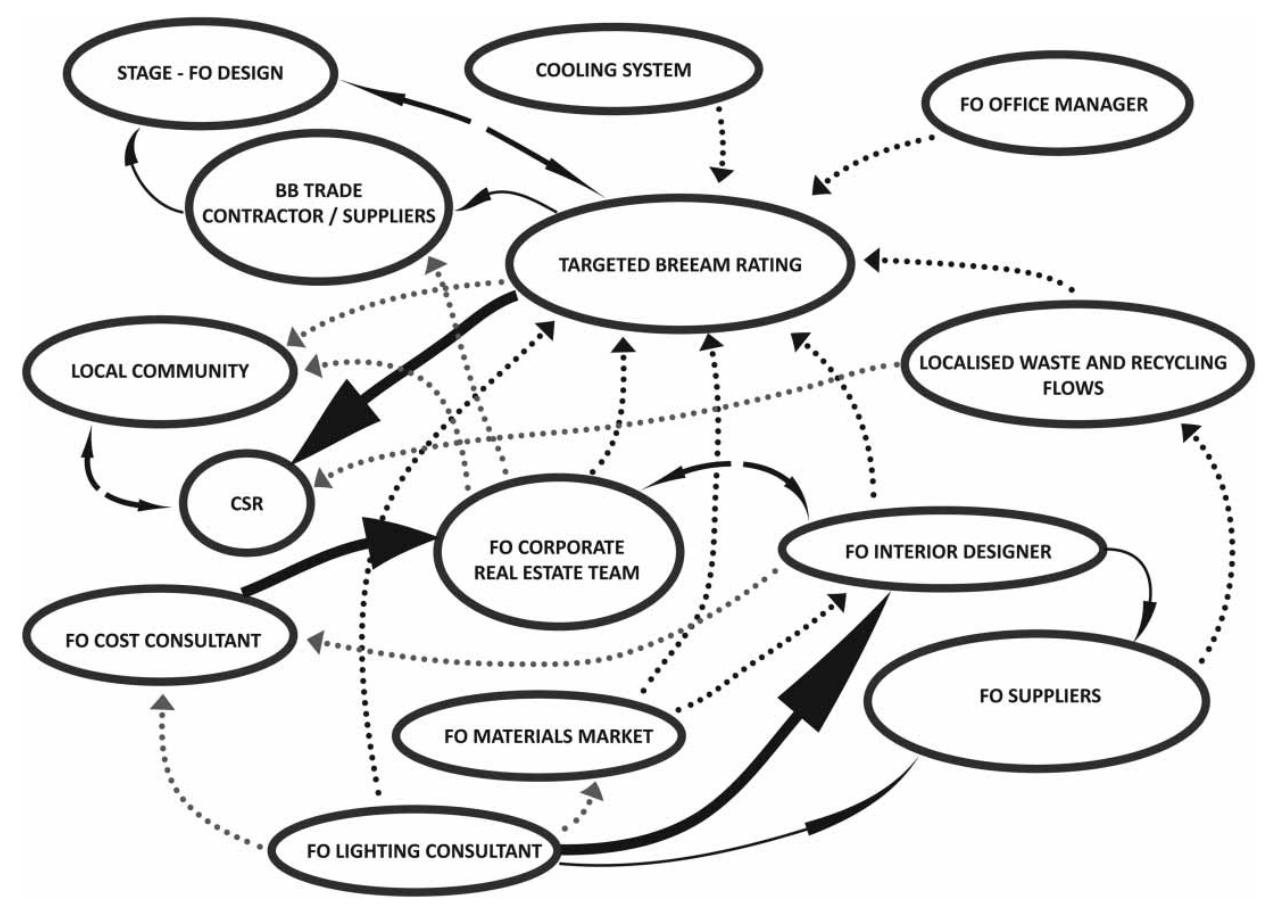

Figure 2. Network map created for the FO main contractor.

tool has an effect on, and is affected by, patterns of relations across socio-technical entities engaged within its network. The BB Developer states:

There are one set of issues which are to do with sustainability which is what is right, what is reasonable and what is responsible. And then there's another thing which is how do you go about demonstrating that. There are limited tools available for that demonstration ... tools like BREEAM that define whether you have a certain degree of sustainability are very rigid, quite constrained, changing quite rapidly and are quite often managed or regulated by people that don't have the resource to adopt or deploy imagination or intelligence and it has increasingly become a series of boxes, and if you can tick those boxes then that says that you've got a certain rating and then that's it. Regardless of whether that actually is more or less sustainable cause that's the criteria they have to measure against.

Consequently, BREEAM may unintentionally become a tool for standardising "easy sustainability": the more difficult or expensive systems might not be engaged in the sustainable building process whilst easier and possibly less-effective sustainable solutions are.

\section{Conclusions}

This research has contributed a socio-technical approach and applied it to an original exploration of BREEAM. In doing so it adopted a network approach to building. The network approach conceived of building development as a process of opportunities for engagement. It viewed the building process as a web of interactivity and opportunity for association. Through this lens it was possible to focus on connections made amongst elements involved in the physical and social construction of a development. 
The socio-technical approach drew on SNA and applied it to the network framework. Specific conceptual insights drawn from SNA included:

- Insight into the interrelations between actors in collectives;

- A focus on the perceptions that social actors hold of other entities within their respective networks;

- The influence of sets of norms and values on actor-network relations;

- The idea that strategic aims and actions influence network associations; and

- The role of power.

However, SNA's primary perspective is on underlying socio-structural contexts. It may not, therefore, in its purest form, be appropriate to probe underlying socio-technological contexts. Thus, this research took an SNA framework and broadened it to include material entities in networks and used materiality to highlight relations between actors. Through this framework this research questioned what those involved in the development understood BREEAM to mean, and how they came together to action BREEAM objectives. This was done with the intention to gain an understanding of what facilitates and what weakens associations within a sustainable building project.

A contribution of this work is that it has highlighted that different professionals involved in a BREEAM building project have different understandings of both what BREEAM is and how a BREEAM rating is achieved. Evidence indicates that meaning is influenced by the immediate contexts in which expertise is engaged: the stronger and more immediate the links are between actors within a network the more likely actors are able to exert influence over others. These links include connections between social actors: individuals, groups and organisations. Social actors have social interests, norms and beliefs which shape their world view and how they construct meaning. Patterns of relations imprint meaning on network actions. This in turn effects actors' engagements with sustainable building practice. PwC, a powerful actor, exerted significant reach and influence across 7 More London's networks. Results suggest representatives of the tenant organisation carried with them norms and beliefs reflecting the "goodness" of the sustainability message of the building. Through positioning representatives across the stages of development, $\mathrm{PwC}$ were able to shape the actions of others to correspond with their own interests: to achieve a highly sustainable building. PwC itself valued sustainability not only for the sake of "doing the right thing", but also because it associated sustainable building with improved recruitment and retention costs and the communication of a corporate image. The association of sustainability with positive corporate image was also a meaning applied to the development project by other organisations involved in the building process. They related BREEAM Outstanding and sustainable building with their own organisations' prestige and, correspondingly, took action to effect more sustainable building. That does not necessarily mean that these actors shared a common understanding of who and what is involved in BREEAM. However, and generally, what they shared was a newly constructed narrative in which they sought to benefit from sustainable building actions.

Yet, another contribution of this work is the incorporation of materiality into network constructions. The socio-technical framework applied here does not consider that material objects exist in a realm separate from the social. Instead, material entities are seen as having the capacity to effect action and materiality is seen as something which is relational. Put another way, material objects are approached neither as objects existing separate from the realm of the social, nor are they seen as things to be approached, utilised and then 
cast aside. Instead, a relational materiality framework allows for socio-technical encounters to take on new associations dependent upon their patterns of relations. Materiality is therefore not inherent within entities but is what Sørensen (2007) phrases a "distributed effect": its characteristics are unique to the ways in which it is organised with other socio-technical entities. In this study the materiality of different lighting system options took on different meanings depending on how it was arranged with other entities in their respective networks. Put another way, the meaning associated with this technical aspect of building design was closely tied to the context in which it was being engaged. Indeed, this is a finding related to the practice of BREEAM as a tool of sustainable building. The different meanings actors associate with BREEAM are a function of their own patterns of relations to it.

While the research undertaken here is more academic in nature, it does fit with current debates on the future of sustainability in building practice. The BRE has announced plans for a "next generation" BREEAM, one taking account of rapidly changing technological developments, contexts, perceptions and practices across a range of stakeholders. It is hoped that research into the less-visible side of sustainable building process - how meaning is constructed and how professionals come together - finds a place in the BRE's updated agenda.

\section{References}

ATLAS.ti, 2009. ATLAS.ti: the knowledge workbench, ATLAS.ti website [online]. Available from: http://www.atlasti.com/index.html [Accessed 5 February 2009].

Balmer, J. and Greyser, S., 2003. Corporate image and reputation: the other realities. In: J. Balmer and S. Greyser, eds. Revealing the corporation: perspectives on identity, image, reputation, corporate branding, and corporate-level marketing. London: Routledge, 173-182.

Banerjee, A. and Solomon, B., 2003. Eco-labelling for energy efficiency and sustainability: a meta-evaluation of US programs. Energy Policy, 31 (2), 109-123.

Barry, C., 1998. Choosing qualitative data analysis software: ATLAS.ti and Nudist compared. Sociological Research Online [online], 3 (3). Available from: http://www.socresonline.org.uk/ socresonline/3/3/4.html [Accessed 5 February 2009].

BDP, 2009a. Stage D report: section 10 - sustainability, Issue 2, BDP client report, London.

BDP, 2009b. BRE environmental \& sustainability standard, BES 5055, Issue 2.0: BREEAM offices 2008 interim assessment report - 7 More London, BDP client report, London.

BRE, 2008. Beyond excellence, BREEAM Supplement, BRE, London.

Callon, M. and Law, J., 1997. After the individual in society: lessons on collectively from science, technology and society. Canadian Journal of Sociology, 22 (2), 165-182.

Clearvision, 2012. What is required of BREEAM? [online]. Available from: http://clearvisionlighting.co.uk/ska-etl-breeam/ [Accessed 10 November 2012].

Cole, R., 1998. Emerging trends in building environmental assessment methods. Building Research and Information, 26 (1), 3-16.

Coviello, N., 2005. Integrating qualitative and quantitative techniques in network analysis. Qualitative Market Research, 8 (1), 39-60.

Davidson, D. and Frickel, S., 2004. Building environmental states: legitimacy and rationalisation in sustainability governance. International Sociology, 19 (1), 89-110.

Ding, G., 2005. Developing a multicriteria approach for the measurement of sustainable performance. Building Research and Information, 33 (1), 3-16.

Doak, J. and Karadimitriou, N., 2007. (Re)development, complexity and networks: a framework for research. Urban Studies, 44 (2), 209-229.

Elam, M., 1999. Living dangerously in a hybrid world. Theory, Culture \& Society, 16 (4), 1-24.

Fuerst, F., et al., 2011. Measuring the financial performance of green buildings in the UK commercial property market: addressing the data issues. Journal of Financial Management of Property and Construction, 16 (2), 163-185. 
Hamedani, A. and Huber, F., 2012. A comparative study of DGNB, LEED and BREEAM certificate systems in urban sustainability. In: M. Pacetti et al., eds. Sustainable city VII. Southampton: WIT Press, $121-132$.

Haughton, G. and Hunter, C., 2003. Sustainable cities. London: Routledge.

Holman, N., 2008. Community participation: using social network analysis to improve developmental benefits. Environment and Planning C, 26 (3), 525-543.

Johnson, J., 1988. Mixing humans and non-humans together: the sociology of a door-closer. Social Problems, 35 (3), 298-310.

Larson, S., et al., 1998. Staff eRecruitment and retention: study results and intervention strategies. Washington, DC: AAMR.

Latour, B., 1987. Science in action: how to follow scientists and engineers through society. Cambridge: Harvard University Press.

Latour, B., 1993. We have never been modern. Brighton: Harvester Wheatsheaf.

Latour, B., 1999. Pandora's hope - essays on the reality of science studies. London: Harvard University Press.

Law, J., 1999. After ANT: complexity, naming and topology. In: J. Law and J. Hassard, eds. Actor network theory and after. London: Blackwell, 1-14.

Lee, W. and Burnett, J., 2008. Benchmarking energy use assessment of HK-BEAM, BREEAM and LEED. Building and Environment, 43 (11), 1882-1891.

Lowton, R., 1997. Construction and the natural environment. Oxford: Butterworth Heinemann.

Miller, E. and Buys, L., 2008. Retrofitting commercial office buildings for sustainability: tenants' perspectives. Journal of Property Investment and Finance, 26 (6), 552-561.

Oyegoke, A., 2001. UK and US construction management contracting procedures and practices: a comparative study. Engineers, Construction and Architectural Management, 8 (5/6), 403-417.

Pryke, S., 2004. Analyzing construction project coalitions: exploring the application of social network analysis. Construction Management and Economics, 22 (8), 787-797.

Pryke, S., 2005. Towards a social network theory of project governance. Construction Management and Economics, 23 (9), 927-939.

Reed, T., et al., 2010. An analysis of LEED and BREEAM assessment methods for educational institutions. Journal of Green Building, 5 (1), 132-154.

Riordan, C., Gatewood, R., and Barnes Bill, J., 1997. Corporate image: employee reactions and implications for managing corporate social performance. Journal of Business Ethics, 16 (4), 401-412.

Rydin, Y., 2010. Governing for sustainable urban development. London: Earthscan.

Sandhu, M. and Helo, P., 2006. A network approach to project business analysis. Engineering, Construction and Architectural Management, 13 (6), 600-615.

Schutt, R., 2008. Investigating the social world: the process and practice of research. London: Pine Forge Press.

Schweber, L. and Harty, C., 2010. Actors and objects: a socio-technical networks approach to technology uptake in the construction sector. Construction Management and Economics, 28 (6), 657-674.

Shediac-Rizkallah, M. and Bone, L., 1998. Planning for the sustainability of community-based health programs: conceptual frameworks and future directions for research, practice and policy. Health Education Research, 13 (1), 87-108.

Sørensen, E., 2007. The time of materiality. Forum: Qualitative Social Research, 8 (1), Article 2.

Tindall, D. and Wellman, B., 2001. Canada as social structure: social network analysis and canadian sociology. Canadian Journal of Sociology, 26 (3), 265-308.

Van der Wetering, J., and Wyatt, P., 2011. Office sustainability: occupier perceptions and implementation of policy. Journal of European Real Estate Research, 4 (1), 29-47.

World Commission on Environment and Development (WCED), 1987. Our common future. Oxford: Oxford University Press. 


\section{Appendix}

Representatives from the following organisations took part in the study:

PricewaterhouseCoopers (known as PwC)

Turner and Townsend

BDP (formerly known as Building Design Partnership)

Overbury

More London Development

Foster + Partners

Mace Group Limited (known as Mace)

Turner and Townsend

Roger Preston \& Partners

Arup

Davis Langdon

Davis Langdon Engineering Services (Mott Green Wall)

Michael J Lonsdale

DWL Ductwork

BRE (formerly known as Building Research Establishment)

Gratte Brothers

TAC (now Schneider Electric)

Hall \& Kay

Townshed Landscape Architects

Susan Deakin Ecology

Southwark Planning Department

Greater London Authority (GLA)

Environment Agency

Honeywell

Ashton Environmental Services 